\title{
CHARACTERIZING SURFACE AND AIR TEMPERATURE IN THE BALTIC SEA COASTAL AREA USING REMOTE SENSING TECHNIQUES AND GIS
}

\author{
Andrzej Chybicki, Ph. D. \\ Marcin Kulawiak, Ph. D. \\ Zbigniew Łubniewski, Assoc. Prof. \\ Gdańsk Univeristy of Technology, Poland
}

\begin{abstract}
Estimation of surface temperature using multispectral imagery retrieved from satellite sensors constitutes several problems in terms of accuracy, accessibility, quality and evaluation. In order to obtain accurate results, currently utilized methods rely on removing atmospheric fluctuations in separate spectral windows, applying atmospheric corrections or utilizing additional information related to atmosphere or surface characteristics like atmospheric water vapour content, surface effective emissivity correction or transmittance correction. Obtaining accurate results of estimation is particularly critical for regions with fairly non-uniform distribution of surface effective emissivity and surface characteristics such as coastal zone areas.

The paper presents the relationship between retrieved land surface temperature, air temperature, sea surface temperature and vegetation indices (VI) calculated based on remote observations in the coastal zone area. An indirect comparison method between remotely estimated surface temperature and air temperature using LST/VI feature space characteristics in an operational Geographic Information System is also presented.
\end{abstract}

Keywords: remote sensing, coastal zone, AVHRR, GIS, surface temperature, air temperature, vegetation index

\section{INTRODUCTION}

In general, the acquisition, processing, integration, and visualization of various kinds of remotely registered data involves several important issues, including limitations in accessibility of sensors, the influence of atmosphere (presence of clouds, the need of atmospheric corrections of measured radiance etc.) [6], as well as insufficient spatial resolution or imperfection of models used for derivation of the desired parameters [17], [20], [23]. This fully applies to well-known applications of remote sensing such as land surface temperature (LST) estimation, emissivity estimation or obtaining more advanced indicators of vegetation density. Attempts to derive LST from satellite observations have been ongoing for several decades. They are mainly focused on using polar orbiting systems such as the Advanced Very
High Resolution Radiometer (AVHRR) [3] because of global coverage, relative high spatial resolution, and short revisiting time. However, accurate LST retrievals require precise determination of atmospheric corrections, as well as land surface emissivity [18], [27]. Both of these effects are addressed eg. by the split-window algorithm (split window technique, SWT), which is widely used due its simplicity [25], [26].

While the knowledge of LST estimation and retrieval is generally well established, the relationship between LST and air temperature $\left(\mathrm{T}_{\text {air }}\right)$ is a subject of some of the current scientific activities and achievements in the field of remote sensing. Certain works in this area explore the negative relationship between a vegetation index (VI), defined 
either as normalized difference vegetation index (NDVI) or fractional vegetation cover (FVC) index, and LST calculated from satellite thermal channel data. A relationship is defined through regression analysis, and extrapolations are performed to obtain a theoretical VI value that represents a full canopy as viewed by the sensor. In this context, measurements from areas with high vegetation density are important because it was observed that for low thermal mass of the canopy, LST will likely be near the local $\mathrm{T}_{\text {air }}$ [22]. Many examples of satellite-based $\mathrm{T}_{\text {air }}$ estimation follow this concept and rely on pixel neighborhood analysis as well as LST/VI relationship.

Because air temperature (obtained e.g. from numerical weather predictions) as well as surface temperature (obtained e.g. via remote sensing) both represent phenomena which take place in a geographical context, the best means of their integration and analysis is offered by a Geographical Information System (GIS), which is a tool for creation, integration, processing and visualization of geographical data. Historically, GIS has many times been applied to integration, processing and dissemination of marine data, including satellite images [15]. In recent years, GIS has been applied to analysis of Global Navigation Satellite System (GNSS) data for the purpose of urban traffic monitoring [13], remote sensing of air and land temperatures [27], temperature monitoring of water balance in India [11] as well as estimating submarine groundwater discharge [28]. However, most of the aforementioned research has been conducted manually, and thus the proposed applications did not form operative systems [16]. At the same time, in [5] it was shown that a GIS is a very effective tool for integration of diverse types of spatial data, while in [30] it was shown that raster data such as satellite images may be successfully investigated by means of Geovisual Analytics. In this context, the application of GIS to comparison of similar data types obtained from diverse sources is a natural consequence.

The paper presents results of a detailed analysis of dependency of $\mathrm{T}_{\text {air }}$ on LST and VI using LST/VI space properties on a regional scale. A dedicated operational WebGIS has been applied to direct processing and integration of LST obtained from satellite images with $\mathrm{T}_{\text {air }}$ obtained from an operational numerical weather prediction (NWP) model. The system processes $\mathrm{T}_{\text {air }}$ and LST in a geographical context and visualizes the results of their analysis with the aid of Geovisual Analytics. Because the presented method exploits the thermal characteristics of tree canopies, its application may be restricted by the forest coverage as well as length of vegetation blooming season in the analyzed area.

\section{THEORY BACKGROUND}

\section{SWT TECHNIQUE}

Algorithms of surface temperature $\left(\mathrm{T}_{\mathrm{s}}\right)$ retrieval from multispectral imagery have been a subject of ongoing studies since the 1970s. Due to wide geographical spread and lack of dense ground in-situ measurements viability, $\mathrm{T}_{\mathrm{s}}$ products are difficult to validate and available measurements are usually scarce and expensive.

For the purpose of $\mathrm{T}_{\mathrm{s}}$ estimation, the authors applied the widely described in literature method of SWT (split-window technique) algorithm. The algorithm relies on calculation of brightness temperatures from several satellite channels on the basis of the Planck Law [6], which connects the temperature $\mathrm{T}_{\mathrm{s}}$ of a radiating surface with the radiation $\mathrm{R}_{\mathrm{T}}$ of the wave length $\lambda$ by the exponential formula:

$$
R_{T}\left(\lambda, T_{s}\right)=\frac{c_{1} \lambda^{-5}}{\exp \left(\frac{c_{2}}{\lambda T_{s}}\right)-1},
$$

where $\mathrm{c}_{1}=1.19104 \cdot 10^{8} \mathrm{~W} \mu \mathrm{m}^{4} \mathrm{~m}^{-2} \mathrm{sr}^{-1}$ and $\mathrm{c}_{2}=1.43877 \bullet 10^{4}$ $\mu \mathrm{m} \mathrm{K}$ are the first radiation constant (for spectral radiance) and second radiation constant respectively. $\mathrm{R}_{T}(\lambda, \mathrm{LST})$ is given in $\mathrm{W} \mathrm{m} \mathrm{m}^{-2} \mathrm{sr}^{-1} \mu \mathrm{m}^{-1}$ if the wavelength is given in $\mu \mathrm{m}$.

In the SWT algorithm, the first-order Taylor series expansion of the Planck Law is used, which allows for linear approximation of the relation between radiance and temperature. Then, the pixel values from satellite channels representing surface temperature are combined (in the case of AVHRR, the $4^{\text {th }}$ and $5^{\text {th }}$ channel, which carry the $10.30-11.30$ $\mu \mathrm{m}$ and $11.50-12.50 \mu \mathrm{m}$ wavelengths, respectively), taking into account the atmospheric conditions and emissivity correction for particular channels. The simplified form of the base SWT equation for base land surface temperature T estimation may be written as follows:

$$
T=T_{4}+A_{S W T}+B_{S W T}\left(T_{4}-T_{5}\right),
$$

where $\mathrm{T}_{4}, \mathrm{~T}_{5}$ - brightness temperature values in ${ }^{\circ} \mathrm{C}$ for $4^{\text {th }}$ and $5^{\text {th }}$ AVHRR channel respectively, and $\mathrm{A}_{\text {SWT }}, \mathrm{B}_{\mathrm{SWT}}$ are coefficients that depend on atmospheric transmittances.

This base LST estimation algorithm has been further improved by applying additional rules which define a more complex relation of AVHRR channel radiations to land surface emissivity and atmospheric transmittance.

\section{EMISSIVITY ESTIMATION}

According to methodology presented in [14] and [25], it was assumed that the average land emissivity for $4^{\text {th }}$ and $5^{\text {th }}$ AVHRR channel $\varepsilon_{\text {avr }}$ and the difference of these channels emissivities $\Delta \varepsilon$ are calculated on the basis of NDVI. Namely, for $0.2<\mathrm{NDVI}<0.5$ the $\varepsilon_{\mathrm{avr}}$ and $\Delta \varepsilon$ are calculated using the following formulae:

$$
\varepsilon_{\text {avr }}=0.971-0.018 P, \Delta \varepsilon=0.006(1-P),
$$

where

$$
P=\frac{(N D V I-0.2)^{2}}{0.09}
$$

whereas for NDVI $>0.5$ they are fixed as: 


$$
\varepsilon_{\text {avr }}=0.985, \quad \Delta \varepsilon=0 .
$$

However, because these rules only apply to areas which exhibit dense vegetation, the pixels for which the NDVI values are less than 0.2 must be discarded from further analysis (e.g. via masking).

\section{CLOUD SCREENING}

In order to remove undesirable (cloud contaminated) pixels from the scene, the approach proposed in [23] was implemented. According to this method, during the analysis of AVHRR imagery, pixels were masked out and not included in further calculations of LST if they met any of the following criteria:

1) channel 1 reflectance $(\mathrm{RED})>0.2$,

2) $\mathrm{Q}=\frac{\mathrm{NIR}}{\mathrm{RED}}<1.2$,

3) $\mathrm{T}_{4}-\mathrm{T}_{5}<-1.5^{\circ} \mathrm{C}$ or $\mathrm{T}_{4}-\mathrm{T}_{5}>4.5^{\circ} \mathrm{C}$.

\section{$\mathrm{T}_{\mathrm{s}}$ ESTIMATION}

Finally, considering calculated water vapour and emissivity, the land surface temperature (LST) is estimated as [24]:

$$
\begin{aligned}
L S T & =T_{4}+1.4 \cdot\left(T_{4}-T_{5}\right)+0.32 \cdot\left(T_{4}-T_{5}\right)^{2}-0.83+ \\
& +(57-5 \mathrm{~W}) \cdot\left(1-\varepsilon_{\text {avr }}\right)-(161-30 \mathrm{~W}) \cdot \Delta \varepsilon
\end{aligned}
$$

In order to estimate sea surface temperature (SST) the McClain formula was applied:

$$
\begin{aligned}
\mathrm{SST}=D_{1} & \cdot T_{4}+D_{2} \cdot\left(T_{4}-T_{5}\right)+D_{3} \cdot\left(T_{4}-T_{5}\right)^{2}+ \\
& +D_{4} \cdot(\sec (\varphi)-1),
\end{aligned}
$$

where $\varphi$ is satellite zenith angle. The $\mathrm{D}_{1}, \mathrm{D}_{2}, \mathrm{D}_{3}$ and $\mathrm{D}_{4}$ coefficient values are adjusted basing on the modelled dependencies of AVHRR channel 4 and 5 values on atmospheric transmittance, as well as comparison of the currently processed image results with reference data if available.

\section{LST/VI SPACE}

The features of LST/VI space have been under the consideration of researchers since early 1980s. The characteristic semi-triangular or trapezoidal shape of the LST/VI scatterplot is caused by low sensitivity of LST to soil moisture variations over vegetated areas, and its higher sensitivity (and thus greater spatial variation) over areas of less vegetation and bare soil.

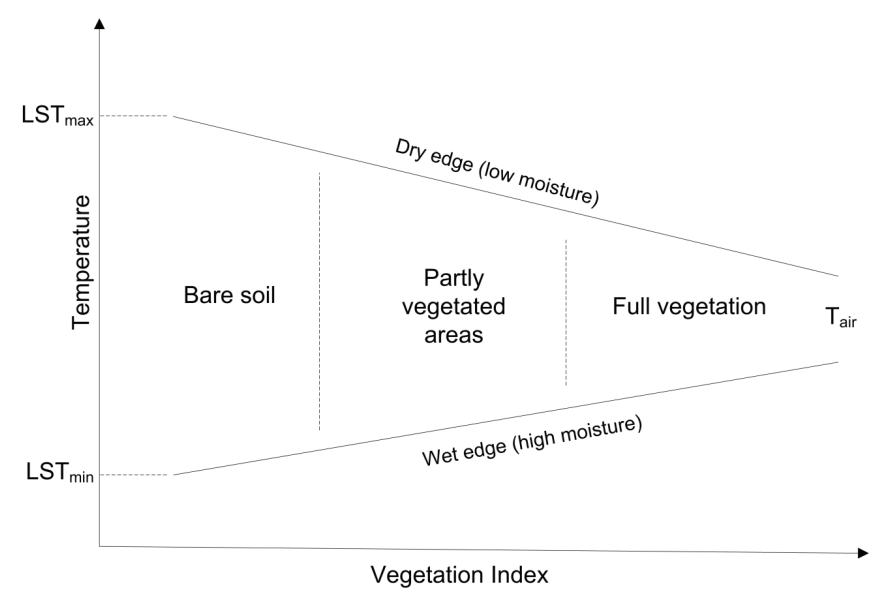

Fig. 1. Graphical representation of LST/VI feature space with key descriptors and physical interpretation

As shown in Fig. 1, the upper border of the triangle shape is the so-called "dry edge" or "warm edge" defined by the locus of points with highest LST, but which contain a differing mix of bare soil and vegetation. For the points located at or near the "dry edge", the latent energy flux due to evapotranspiration is assumed to be equal or close to zero, and the direction of the sensible heat flux is from the soil and vegetation to the air, with decrease of its absolute value from the left to the right side of the LST/VI plot. Likewise, the bottom edge, often referred as "wet edge" or "cold edge", corresponds to the set of pixels with lowest LST that have varying amounts of vegetation cover and are characterized by the maximum soil water content. For the points located at or near this edge, the latent energy flux due to evapotranspiration is assumed to be maximum within the area of a given VI value range, and the direction of the sensible heat flux is from the air to the soil and vegetation, with decrease of its absolute value from the left to the right side of the LST/VI plot.

The area on the left side of the triangle is assumed to reflect the combined effects of soil water content and topography variations across areas of bare soil, while the right side (and especially the triangle's apex) equates to the status of full vegetation cover. The points filling the interior of the triangular space represent pixels with varying vegetation cover, somewhere between bare soil and dense vegetation. Note that, for data points having the same or close VI values, LST can range markedly. The explanation of this phenomena is that for an area well supplied with water, transpiration acts to cool vegetation very effectively, but as vegetation undergoes water stress the plant tends to close its stomata - with the resulting transpiration decrease leading to an increase of leaf temperature. Thus, for pixels with the same VI, those with minimum LST are assumed to have the strongest evaporative cooling, while those with maximum LST represent those with the weakest evaporation. Therefore, the "dry edge" of the shape is considered to represent the upper limit of evaporation for the different vegetation conditions found within investigated area, whereas the reverse is implied for the "cold edge". 


\section{DATA DESCRIPTION}

\section{STUDY AREA}

The presented study was conducted for the territory of the Gulf of Gdańsk, localized in the Pomorskie Voievodship of Poland, on the Southern shores of the Baltic Sea. The elevation in the area ranges from $1.8 \mathrm{~m}$ below sea level in the Vistula marshes to 329 meters above sea level delimited by the Wieżyca peak. Most of the voievodship (55\%) is composed of coastal areas. The remaining $45 \%$ is spread between agriculture (19\%), vegetation such as coniferous forest, mixed forest or natural grasslands (16\%), urban areas (8\%) and others (2\%). The average summer daily temperatures in the area hover around $16.5^{\circ} \mathrm{C}$. The average annual precipitation ranges between $400 \mathrm{~mm}$ and $600 \mathrm{~mm}$, which makes for some diverse hydrological and vegetation conditions.

A geographical view of the investigated area is given in Fig. 2.

\section{WRF}

An alternative method for obtaining air temperatures for regional and local scale applications employs the use of numerical weather prediction models such as the Weather Research and Forecast (WRF) model. WRF is a next-generation mesoscale model, designed and developed by several organizations, such as the National Center for Atmospheric Research (NCAR), National Centers for Environmental Prediction (NCEP), National Oceanic and Atmospheric Administration (NOAA), National Aeronautics and Space Administration (NASA), Air Force Weather Agency (AFWA), and a number of collaborating institutes and universities.

Meteorological data from an NWP can be helpful during model fitting in evapotranspiration estimation, i.e. in methods for water vapour content retrieval using low resolution multispectral imagery [4], modelling solar radiation [21], radiometric correction within multispectral imaging and others.

The WRF instance used in this study was installed and configured internally at the Department of Geoinformatics in the Faculty of Electronics, Telecommunications and Informatics of Gdańsk University of Technology. The model is ran operationally by the Department since 2011 . The process of configuration and adjustment of the model for local conditions was performed for several years in order to properly establish and optimize several important elements, including the parameterization scheme, microphysics scheme, surface energy flux scheme, computing grid spatial (vertical and horizontal) resolution, computing domain localisation and nesting. In the current configuration the system generates 48-hour forecasts, four times per every 24 -hour operating period. The forecasts are produced in a $4 \mathrm{~km}$ local domain, nested in a $12 \mathrm{~km}$ grid regional domain. The boundaries between the local and

Fig. 2. Map of the analysed area. Spatial distribution of land surface types, source: Corine Land Cover data (2006)

\section{IN-SITU OBSERVATION}

Air temperature observations in the presented research were retrieved from the Land SYNOP station network which transmits observations, made on land, in the form recommended by WMO (World Meteorological Organization) standards as a SYNOP message. Currently, WMO station network consists of over 10.000 synoptic stations all over the world, and over 60 in the territory of Poland, producing hourly, 3-hour and 6-hour reports. The distribution of observation stations is far from being uniform, and does not take into account the spatial structure of environment conditions. Because of this in many situations the interpolation of meteorological air temperature observations in order to obtain data in high resolution grid may not produce satisfying results. regional domain are presented in Fig. 3. The model utilizes Grell-Devenyi ensemble parameterization scheme [10], Ferrier operational microphysics scheme [8], Noah Land Surface Model physics scheme [2] unified by NCEP/NCAR/AFWA and GFDL radiation scheme [7]. Initialization and boundary conditions data is retrieved from GFS model downloaded from NCEP online services which also provide SST in their RTG_SST_HR product i.e. for the Baltic Sea.

\section{AVHRR}

Satellite data used in the presented research was obtained from a dedicated 1.5m-wide HRPT/MetOp-A/B local satellite ground station, operated by the Department. The NOAA/ MetOp AVHRR imagery is retrieved from the satellite station High Resolution Picture Transmission (HRPT) stream and converted to GeoTIFF data files in spatial resolution $1.1 \mathrm{~km}$ by $1.1 \mathrm{~km}$ per pixel. The range of recorded photographs entirely 
covers the study area described in section 3.1. The applied cartographic projection is Lambert Azimuth Equal Area (LAEA) with $19^{\circ} \mathrm{E}$ and $52^{\circ} \mathrm{N}$ as central meridian and central parallel respectively (geometric centre of researched area). The HRPT stream also contains information about solar zenith $\left[^{\circ}\right]$, solar azimuth $\left[^{\circ}\right]$, nadir to pixel $\left[^{\circ}\right]$, satellite inclination $\left[^{\circ}\right]$ and raw and calibrated data for channels 1-5, which can be utilized in other applications of remote sensing techniques.

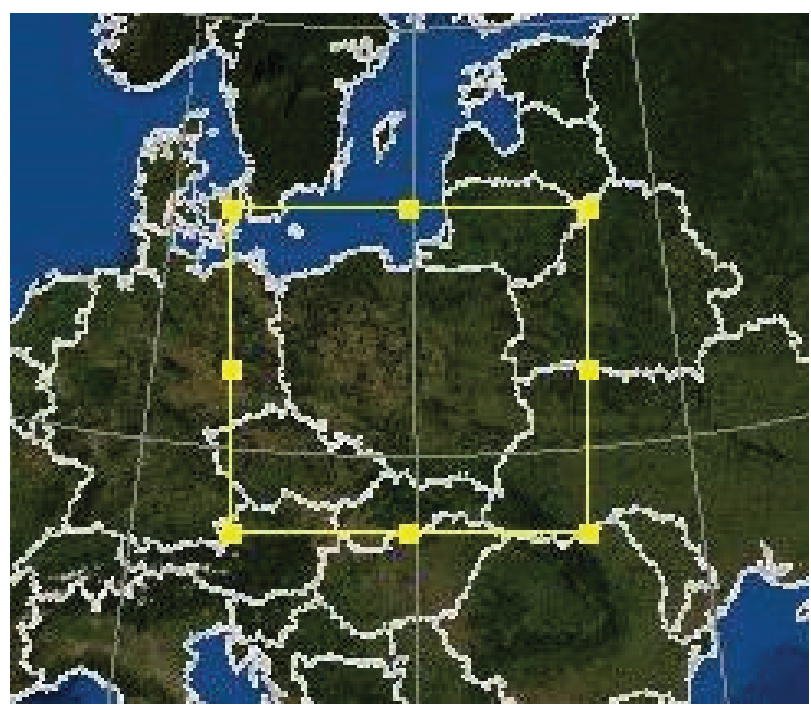

Fig. 3. The boundaries between the local domain (4 $\mathrm{km}$ resolution) and regional domain (12 km resolution) used in the applied instance of the WRF model

\section{ALGORITHM IMPLEMENTATION ENVIRONMENT}

In order to automate the process of data analysis, the authors have developed an operational system which integrates data from the AVHRR satellite station as well as results of numerical weather predictions in a common geographical context. The general architecture of the system is shown in Fig. 4.

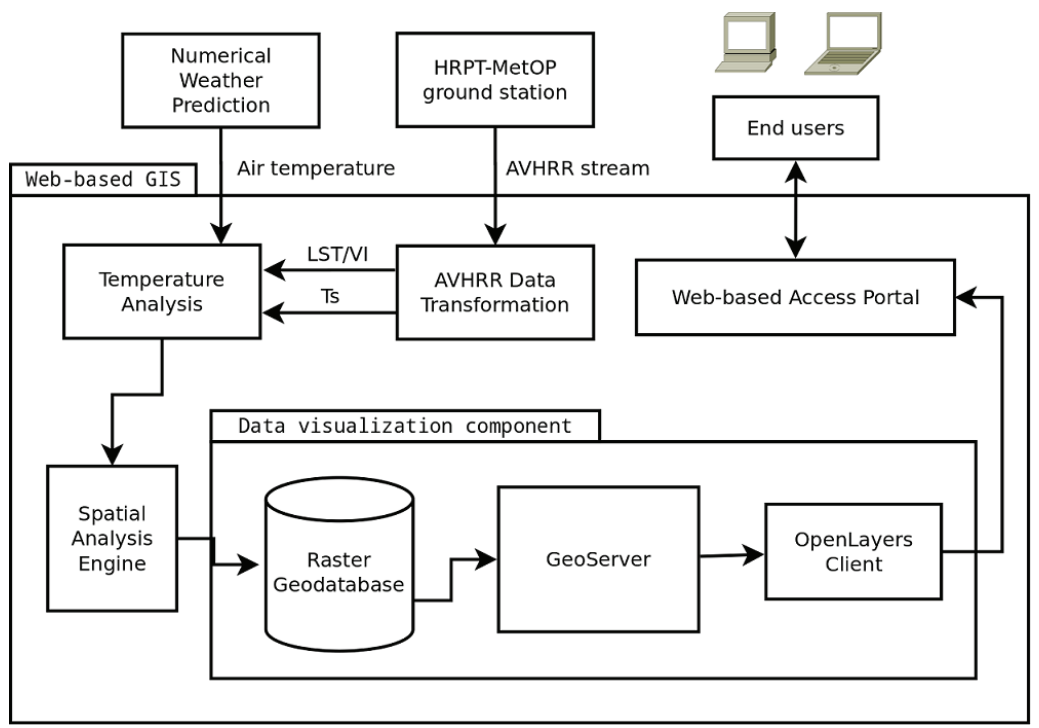

Fig. 4. Architecture of the GIS for integration and analysis of temperature data from different sources
The system consists of several modules, each responsible for specific functionality. Data from two external sources (the WRF Numerical Weather Prediction model and HRPTMetOp satellite ground station, namely) is acquired and processed inside a Web-based Geographic Information System in order to accurately perform their analysis. First, data from HRPT-MetOp ground station is transformed from a HRPT stream to a geospatial data format. Then, the Temperature Analysis module imports the results of Numerical Weather Prediction for the same date and hour in rotated lat/lon projection and transforms it to common Lambert Azimuth Equal Area (LAEA) projection in the same spatial resolution as the obtained AVHRR data. The module then obtains LST/VI parameters of the analysed scene. The module produces georeferenced imagery of $T_{s}$ and $T_{\text {air }}$ in LAEA projection, which is passed on to the Spatial Analysis Engine. The Spatial Analysis Engine uses Geovisual Analytics to perform temperature consistency analysis between the source images. The results are stored in a spatial geodatabase from which they are retrieved by the GeoServer, which is a Web Map server with excellent support for open standards of spatial data exchange such as OGC Web Feature Service and Web Map Service. The latter is used to serve thematic layers to the Web GIS client, which uses the Open Source OpenLayers javcascript library to provide the end users with a rich GIS functionality inside a standard Web browser, without the need for additional plugins. Through the client, the users may view the results of the latest temperature consistency analysis and compare them to source data or available satellite imagery at any given time.

\section{RESULTS}

The main goal of the presented research was to analyse the relationship between air temperature obtained from NWP and surface temperature retrieved from AVHRR imagery in the context of LST/VI space properties for a region with high surface type diversity. As it is known, there is significant correlation between these two quantities, however not much attention has been paid to this subject. In general, air temperature is less spatially variable than LST. This being said, air temperature depends to a greater extent on global weather conditions than on surface characteristics and incoming radiation. Verification of air temperature estimation is relatively easy, as it can be compared with in-situ observations from SYNOP. However, verification of LST estimation causes serious difficulties due to wide geographical spread, spatial resolution of radiometer, atmospheric fluctuations etc.

Obtaining good quality AVHRR datasets for the region of Central Europe is not a trivial task due to the fact that during most of the vegetation blooming season the atmosphere contains a large amount of water vapour and clouds. High relative air humidity (60-80\%) during the day causes variations in atmosphere transmittance which in turn affects values recorded by satellite thermal channels 
and makes LST retrieval less accurate. This makes it hard to retrieve non-cloud-contaminated datasets for most of the considered period.

First stage of work was focused on calculating the results of LST/VI space for the analysed scene (Fig. 5).

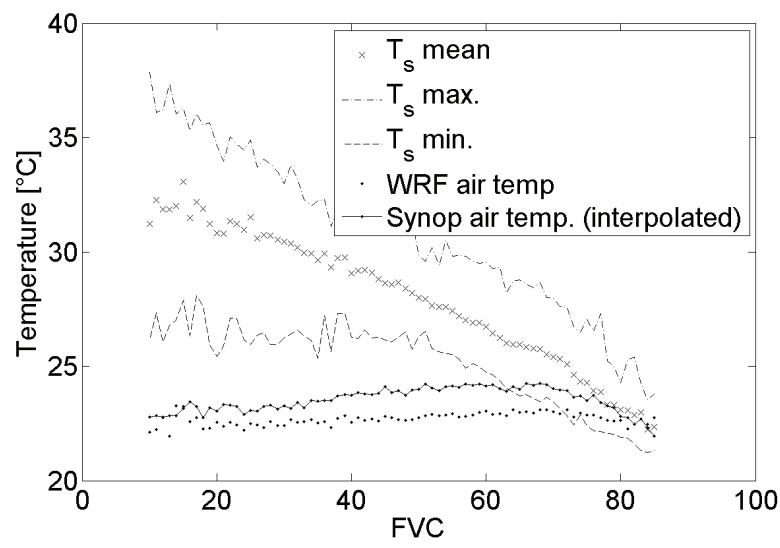

Fig. 5. LST/VI space graphic representation containing LST data, WRF NWP air temperature $\left(T_{\text {air }}\right)$ and interpolated SYNOP observation data

In the presented case, average air temperature (from NWP and SYNOP stations) was about $23^{\circ} \mathrm{C}$. As expected, LST values were higher than $T_{\text {air }}$ values due to high radiation $\left(300-500 \mathrm{~W} / \mathrm{m}^{2}\right)$ caused by cloudless sky conditions and high sun zenith angle. According to Fig. 5, a significant rise of LST along with decreasing vegetation (expressed as fractional vegetation index) can also be observed. The presented results also appear to confirm the hypothesis that $T_{\text {air }}$ and LST are equal for high vegetation areas. This applies to WRF $T_{\text {air }}$ and SYNOP observation as well.

Since the respected region consists of highly diverse surface types (forests, urban areas, agriculture, sea and others), a dedicated procedure of $T_{s}$ estimation was proposed. In order to estimate surface temperature for this diversified region, the satellite images acquired directly from a ground station were processed by the dedicated GIS which applied two separate masks: one mask that removes pixels that contain sea area, and a second mask that removes pixels of land surface area. Both masks also remove pixels contaminated with clouds. Once the area has been separated into land and sea, the land region is analysed using the LST estimation procedure described in [5], [6], [9], while the sea area is processed using the algorithm defined in [11] for SST estimation. After both procedures are accomplished, the hybrid result (containing data from both sources) is returned in the form of a single product. The resulting thematic layer, made available via the GIS Web Map Service, contains surface temperature $\left(T_{s}\right)$ which is presented in Fig. 6.

This particular type of product is styled using a standard temperature colour bar in which areas of low temperature are represented in dark blue, and the hottest areas are coloured in dark red. This allows for easier analysis and interpretation of the produced data.

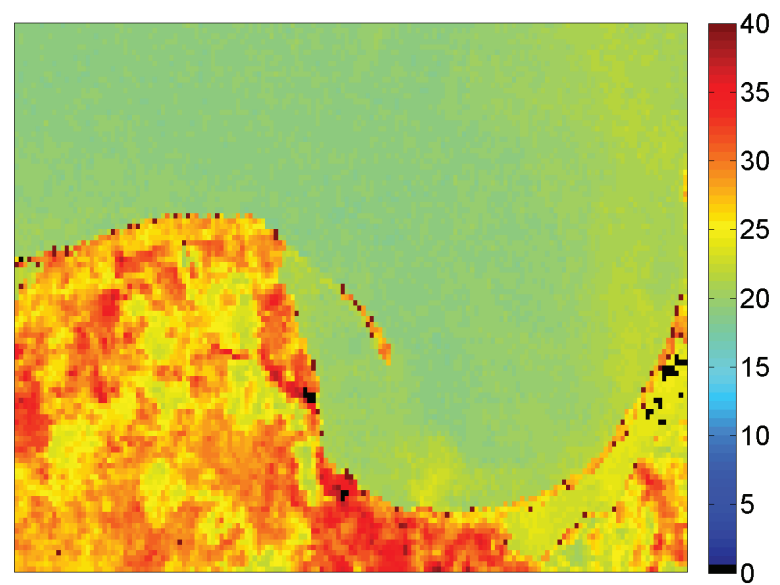

Fig. 6. Surface temperature $(T)$ estimation using hybrid approach. Black pixels represent areas where due to low resolution of source data the algorithm was unable to categorize the pixel as neither land nor sea type.

The close integration of both satellite $(T)$ and weather prediction model $\left(T_{a i r}\right)$ data in a geographical context allows for their advanced analysis via Geovisual Analytics. Thus, for every pixel of data in the AVHRR image, the GIS retrieves the respective pixel of WRF data and performs their consistency analysis. The resulting images form a time series in the Web GIS and may be viewed by means of WMS with a TIME parameter. This allows one to not only view temperature consistency for selected dates in an organized manner, but also enables analysis of differences between times of day as well as over longer time periods. Fig. 6 shows a sample comparison of difference between $T_{\text {air }}$ and $T_{s}$ for the analysed scene within the Web-GIS client. By implementing the paradigms of Geovisual Analytics, the resulting image depicts the level of difference using user-perceptual Ordinal Pseudocolor Sequencing. Areas where the difference is less than $1^{\circ} \mathrm{C}$ are marked in green, while larger differences are marked in yellow $\left(2-3^{\circ} \mathrm{C}\right)$, orange $\left(3-4^{\circ} \mathrm{C}\right)$ and red (greater than $\left.5^{\circ} \mathrm{C}\right)$.

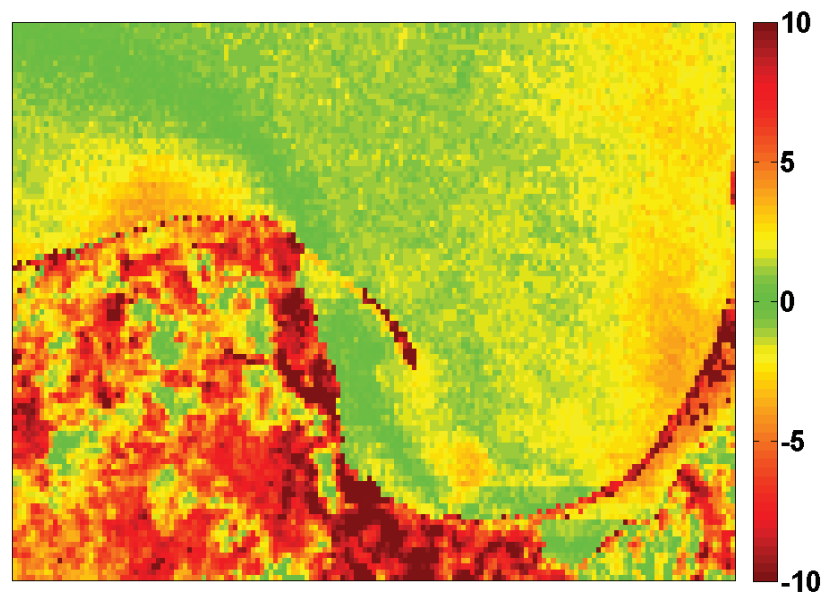

Fig. 7. Geovisual Analysis of difference between modelled $T_{\text {air }}$ and $T_{s}$ for investigated region

As it can be seen in Fig. 7, in the analysed coastal area of the Gulf of Gdańsk there are several areas which exhibit very high similarities between surface temperature $\left(T_{s}\right)$ obtained from 
the AVHRR sensor and air temperature $\left(T_{\text {air }}\right)$ produced by the WRF model. In particular, although the differences between $T_{s}$ and $T_{\text {air }}$ often exceed $5^{\circ} \mathrm{C}$ and reach as high as 10 degrees in some areas, there are certain places in which the gap between both values virtually disappears. The nature of this phenomenon over land can be easily discerned by comparing the geographical layout of the temperature differences with the vegetation coverage of the area, as depicted in Fig. 8 .

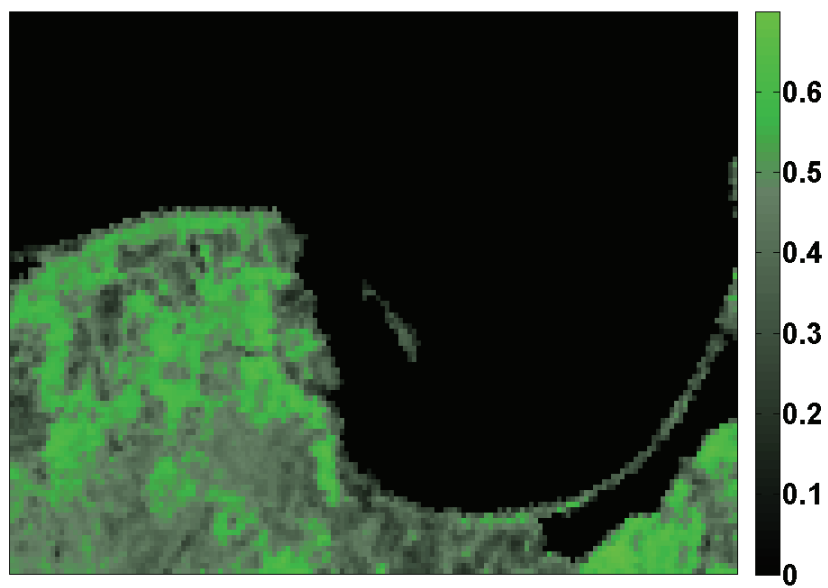

Fig. 8. NDVI spatial distribution for investigated area

As it can be observed, the biggest difference between $T_{\text {air }}$ and $T_{s}$ is noticeable for land regions with sparse vegetation (low FVC). In this case LST is higher than $T_{\text {air }}$ by more than 5 ${ }^{\circ} \mathrm{C}$. At the same time, the smallest differences may be observed for densely vegetated areas (shown in light green in Fig. 8) and areas of the Baltic Sea basin.

\section{CONCLUSIONS}

The presented work deals with the important problem of air temperature estimation using remote sensing techniques. The described research methodology uses an automated Web-GIS with direct access to AVHRR images from a satellite ground station as well as data from an operational NWP model. The images provide information on land surface properties with relatively good temporal resolution, while having moderate spectral and spatial resolution at the same time. In most meteorological applications AVHRR provides information on water temperature, cloud properties or land emissivity temperature etc. However, it does not provide information about air temperature. The presented GIS integrates results of satellite temperature analysis in a geographical context and enables their automated comparison to temperature estimation obtained from the numerical weather model. The results of the presented analysis are presented in semi-real time in the form of thematic layers, generated in accordance to the paradigms of Geovisual Analytics. The obtained results support the hypothesis that air temperature and surface temperature are equal for high vegetation areas, which has also been verified using SYNOP observations.

It should be noted that because the presented approach analyses the relationship between the values of air and surface temperatures by exploiting the thermal characteristics of tree canopies, its application may be restricted by the forest coverage as well as length of vegetation blooming season in the analyzed area. This being said, the presented results prove that properties of LST/VI space can provide information for air temperature estimation, particularly for areas with a highly diverse distribution of surface type.

\section{REFERENCES}

1. Chen F., Dudia J.: Coupling an advanced land-surface / hydrology model with the Penn State/NCAR MM5 modeling system. Monthly Weather Review, 129/2001, 569-585.

2. Chen, F., K. Mitchell, J. Schaake, Y. Xue, H. Pan, V. Koren, Y. Duan, M. Ek, and A. Betts, 1996: Modeling of landsurface evaporation by four schemes and comparison with FIFE observations. J. Geophys. Res., 101, 7251-7268.

3. Cracknell A. P.: The Advanced Very High resolution Radiometer (AVHRR). Taylor and Francis, 1997.

4. Cristobal J., Poyatos R., Ninyerola M., Llorens P.: Combining remote sensing and GIS climate modelling to estimate daily forest evapotranspiration in a Mediterranean mountain area. Hydrology and Earth System Sciences Discussions, 15/2011, 1563-1575.

5. Dąbrowski J., Kulawiak M., Moszyński M., Bruniecki K., Kamiński Ł., Chybicki A., Stepnowski A.: Real-time web-based GIS for analysis, visualization and integration of marine environment data. In: Information Fusion and Geographic Information Systems, Springer Berlin Heidelberg, 2009, 277-288.

6. Dash P.: Land Surface Temperature and Emissivity Retrieval from Satellite Measurements. Institut fur Meteorologie und Klimaforshung, 2005.

7. Donner L. J., Wyman B. L., Hemler R. S., Horowitz L.W., Ming Y., Zhao M., Golaz J.-C., Ginoux P., Lin S.J., Schwarzkopf M. D., Austin J., Alaka G., Cooke W. F., Delworth T. L., Freidenreich S. M., Gordon C. T., Griffies S. M., Held I. M., Hurlin W. J., Klein S. A., Knutson T. R., Langenhorst A. R., Lee H.-C., Lin Y., Magi B. I., Malyshev S. L., Milly P. C., Naik V., Nath M. J., Pincus R., Ploshay J. J., Ramaswamy V., Seman C. J., Shevliakova E., Sirutis J. J., Stern W. F., Stouffer R. J., Wilson R.J., Winton M., Wittenberg A. T., Zeng F.: The dynamical core, physical parameterizations, and basic simulation characteristics of the atmospheric component AM3 of the GFDL Global Coupled Model CM3. Journal of Climate, 24(13)/2011, 3484-3519.

8. Ferrier B. S., An efficient mixed-phase cloud and precipitation scheme for use in operational NWP models, Eos, Trans. Amer. Geophys. Union, 86(18)/2005. 
9. Gillies R. R., Carlson T. N., Cui J., Kustas W. P., Humes K. S.: Verification of the 'triangle' method for obtaining surface soil water content and energy fluxes from remote measurements of the Normalized Difference Vegetation Index NDVI and surface radiant temperature. International Journal of Remote Sensing 18/1997, 3145-3166.

10. Grell, G. A., D. Devenyi: A generalized approach to parameterizing convection combining ensemble and data assimilation techniques. Geophys. Res. Lett., 29/2002, 1693-1696.

11. Jain S. K., Hariprasad V., Choudhry A.: Water Balance Study for a Basin Integrating Remote Sensing Data and GIS. Journal of the Indian Society of Remote Sensing 39/2011, 259-270.

12. Janjic Z. I., Gerrity J. P., Nickovic S.: An Alternative Approach to Nonhydrostatic Modeling. Monthly Weather Review, 129/2001, 1164-1178.

13. Janowski A., Nowak A., Przyborski M., Szulwic J.: Mobile indicators in GIS and GPS positioning accuracy in cities. In: Rough Sets and Intelligent Systems Paradigms, Springer International Publishing, 2014, 309-318.

14. Julien Y., Sobrino J. A., Mattar C., Ruescas A. B., JimenezMunoz J. C., Soria G., Hidalgo V., Atitar M., Franch B., Cuenca J.: Temporal analysis of normalized difference vegetation index (NDVI) and land surface temperature (LST) parameters to detect changes in the Iberian land cover between 1981 and 2001. International Journal of Remote Sensing, 32/2011, 2057-2068.

15. Kulawiak M., Chybicki A., Moszyński M.: Web-based GIS as a tool for supporting marine research. Marine Geodesy, 33/2010, 135-153.

16. Kulawiak M., Łubniewski Z.: SafeCity - A GIS-based tool profiled for supporting decision making in urban development and infrastructure protection. Technological Forecasting and Social Change, 89/2014, 174-187.

17. Lillesand T. M., Kiefer R. W.: Remote Sensing and Image Interpretation. John Wiley, New York, 1987.

18. McClain E. P., Pichel W. G., Walton C. C.: Comparative performance of AVHRR-based multichannel sea surface temperatures. Journal of Geophysical Research, 90/1985, 11587-11601.

19. Michalakes J., Dudhia J., Gill D., Henderson T., Klemp J., Skamrock W., Wang W.: The Weather Research and Forecast Model: Software Architecture and Performance. Proceedings of the $11^{\text {th }}$ ECMWF Workshop on the Use of High Performance Computing in Meteorology, 25-29 October 2004, Reading, U.K., Ed. George Mozdzynski.
20. Moszyński M., Kulawiak M., Chybicki A., Bruniecki K., Bieliński T., Łubniewski Z., Stepnowski A., Innovative Web-Based Geographic Information System for Municipal Areas and Coastal Zone Security and Threat Monitoring Using EO Satellite Data, Marine Geodesy, Volume $38(3) / 2015,203-224$.

21. Pons X., Ninyerola M.: Mapping a topographic global solar radiation model implemented in a GIS and refined with ground data. International Journal of Climatology 28/2008, 1821-1834.

22. Prihodko L., Goward S. N.: Estimation of air temperature from remotely sensed surface observations. Remote Sensing of Environment, 60/1997, 335-346.

23. Qin Z., Dall'Olmo G., Karnieli A., Berliner P.: Derivation of split window algorithm and its sensitivity analysis for retrieving land surface temperature from NOAA Advanced Very High Resolution Radiometer data. Journal of Geophysical Research: Atmospheres (1984-2012), 106/2001, 22655-22670.

24. Riddering J. P., Queen L. P.: Estimating near-surface air temperature with NOAA AVHRR. Canadian Journal of Remote Sensing, 32/2006, 33-43.

25. Sobrino J. A., Raissouni N.: Toward remote sensing methods for land cover dynamic monitoring: application to Morocco. International Journal of Remote Sensing 21/2000, 353-366.

26. Ulivieri C., Castronuovo M. M., Francioni R., Cardillo A.: A split window algorithm for estimating land surface temperature from satellites. Advances in Space Research, 14/1996, 279-1292.

27. Vidal A.: Atmospheric and emissivity correction of land surface temperature measured from satellite using ground measurements or satellite data, International Journal of Remote Sensing, 12/1991, 2449-2460.

28. Wilson J., Rocha C.: Regional scale assessment of Submarine Groundwater Discharge in Ireland combining medium resolution satellite imagery and geochemical tracing techniques. Remote Sensing of Environment, 119/2012, 21-34.

29. Zheng X., Zhu J., Yan Q.: Monthly Air Temperatures over Northern China Estimated by Integrating MODIS Data with GIS Techniques. Journal of Applied Meteorology and Climatology, 52/2013, 1987-2000.

30. Zurita-Milla R., Blok C., Retsios V.: Geovisual analytics of Satellite Image Time Series. International Environmental Modelling and Software Society (iEMSs) 2012 International Congress on Environmental Modelling 
and Software. Managing Resources of a Limited Planet: Pathways and Visions under Uncertainty, Sixth Biennial Meeting, Leipzig, Germany, 2012.

\section{CONTACT WITH THE AUTHOR}

Andrzej Chybicki

Gdańsk University of Technology

Narutowicza street 11/12

80-233 Gdańsk, Poland,

telephone: +4858347 1326

e-mail: andrzej.chybicki@pg.gda.pl

\section{Poland}

